\title{
THE DYNAMIC TRANSFORMATION OF FERRITE ABOVE AE3 AND THE CONSEQUENCES ON HOT ROLLING OF STEELS
}

\author{
Fulvio Siciliano ${ }^{\prime}$ \\ Samuel Filgueiras Rodrigues ${ }^{2}$ \\ Clodualdo Aranas Jr ${ }^{3}$ \\ John Joseph Jonas ${ }^{4}$
}

\begin{abstract}
The occurrence of dynamic transformation of ferrite (DTF) above Ae 3 has recently been proven to be an operative mechanism during hot deformation. This work is a preliminary description of the effects of DTF on the thermo-mechanical control processing (TMCP) in hot rolling of steels and a summary TMCP strategies is presented. The occurrence of dynamic transformation of ferrite in the austenite region is proved by means of synchrotron light diffraction methods. This phase transformation mechanism is taken into consideration and its effects on TMCP are proposed.
\end{abstract}

Keywords: TMCP; Hot rolling; Microalloyed steels; Dynamic transformation of ferrite.

\section{INTRODUCTION}

Important metallic materials such as steels, copper and aluminum alloys undergo to at least one thermomechanical control processing step during fabrication. Important studies have been carried out along the last decades by performing physical and numerical simulation of the hot rolling process. Among the pioneers on this field there are LeBon [I], Sellars [2], McQueen and Jonas [3] working mostly with the interpretation of stress-strain curves also nicknamed as "mechanical metallography". Industrial TMCP requires planning, metallurgical knowledge and tight process control to be successful. It allows to produce a fine-grained material resulting in high levels of strength and toughness in the final product [4].

In this paper, it will be analyzed the controlled rolling strategies for steels which are mainly based on the recrystallization principles. Firstly the recrystallization controlled rolling where the main objective was to reduce thickness at lower roll forces in the mill. More "recent" processes such as conventional controlled rolling and dynamic recrystallization controlled rolling. The dynamic transformation of ferrite is considered during rolling as well as the proposed interactions of this mechanism with the rolling strategies. Finally, the strategies will be compared and aligned with the Seven Laws of Recrystallization, published in 1952 by Burke and Turnbull [5], where the summary of virtually all processes fall in.

\section{THE TMCP STRATEGIES IN STEEL ROLLING}

The concepts discussed here will be exemplified on a multi-stand flat tandem hot mill. They can be applied to other hot rolled products such as plates or bars as well as different mill configurations such as heavy plate, Steckel and seamless pipe mills. The evolution of the techniques are related to the increasing mill capabilities in terms of force and control. The three traditional rolling strategies are described as follows [6].

\section{I Recrystallization Controlled Rolling (RCR)}

This approach is normally used for thick plates and thick-walled seamless tubes, where the rolling loads are close to the upper limit of the mill [7]. The high rolling temperatures involved (usually above $950^{\circ} \mathrm{C}$ ) cause full recrystallization to take place between passes. For this purpose, $\mathrm{Ti}$ and $\mathrm{V}$ are added, allowing recrystallization to go to completion all along the schedule, but preventing grain growth from taking place when recrystallization is complete well before the next pass. The Ti additions lead to the precipitation of TiN during continuous casting. This TiN dispersion prevents the occurrence of extensive grain growth. $V$ additions will cause precipitation of $\mathrm{VN}$ in the ferrite region, increasing strength. These conditions are not suited to producing the finest grain sizes; nevertheless, mill load limitations make this approach necessary in some cases. The RCR process should be employed in association with fast cooling rates in order to refine ferritic grain sizes after transformation.

\subsection{Conventional Controlled Rolling (CCR)}

The main purpose of CCR is to produce a work hardened austenite after the last stand in order to increase the number of nucleation sites for the austenite-to-ferrite

'Gleeble Simulation Testing Solutions, Dynamic Systems Inc., Poestenkill, NY, United States of America. E-mail: fulvio.siciliano@gmail.com; fulvio@gleeble.com 2Programa de Graduação em Engenharia de Materiais, Instituto Federal de Educação, Ciência e Tecnologia do Maranhão, São Luis, MA, Brasil. ${ }^{3}$ Department of Mechanical Engineering, University of New Brunswick, Fredericton, NB, Canada. ${ }^{4}$ Materials Engineering, McGill University, Montreal, QC, Canada.

2176-1523 (C) 2020. Siciliano et al. Published by ABM. This is an Open Access article distributed under the terms of the Creative Commons Attribution License, which permits unrestricted use, distribution, and reproduction in any medium, provided the original work is properly cited. 
transformation. This leads to production of the finest ferrite grain sizes, improving mechanical properties such as the toughness and yield strength. The fine microstructures formed in this way are responsible for high yield strength and toughness levels in the hot rolled product.

This approach generally involves the use of high reheat temperatures so as to dissolve the microalloying elements $\mathrm{Nb}$ and $\mathrm{V}$ completely in the austenite. Then, roughing is carried out, at temperatures above the temperature of non-recrystallization, Tnr, allowing full softening between passes and keeping the microalloying elements in solution. Finally, finishing is applied to flatten or "pancake" the austenite grains at temperatures below the Tnr. The solute drag acting on the moving grain boundaries and the particle pinning (after the precipitation of $\mathrm{Nb}(\mathrm{C}, \mathrm{N})$ ) retard or even prevent the occurrence of recrystallization.

\subsection{Dynamic Recrystallization Controlled Rolling}

The DRX mechanism has always been extensively studied by means of high-temperature mechanical testing, however, one of the first evidences of DRX in industrial mills was reported by Sarmento and Evans in 1992 [8]. Later, the research group of Prof. J.J. Jonas at McGill University performed extensive studies on the subject, mostly with industrial data from several steel companies around the world [9-14]. The unexpectable mean-flow-stress drops observed in a few cases show evidences of DRX. A mathematical model has been proposed using industrial data and backed up with intense use of physical simulation experiments by means of torsion tests [9-14]. This type of process consists of inducing DRX in one or more passes during the rolling schedule. This can be done either by applying large single strains to the material or via strain accumulation. Both methods will allow the total strain to exceed the critical strain for the initiation of DRX. The former can be applied in the initial passes at high temperatures. The latter can occur at relatively low temperatures, in the last passes, after the strain has accumulated in the previous passes. Some of the benefits of this approach involve the intense grain refinement caused by DRX when high strain rates and large strains are applied (single peak behavior in the stress-strain curve). Circumstantial evidence for the occurrence of DRX in seamless tube rolling $[15,16]$ and hot strip mills $[8,17]$ can be found in the literature .

Figure I illustrates schematically the three controlled rolling approaches described above for a hypothetical 5 -pass schedule. Knowledge of the rolling parameters and process limitations associated with each method makes possible the design of rolling schedules to fit the needs and constraints of each case.

The Figures 2 to 4 show the schematic microstructural evolution for the above three strategies.
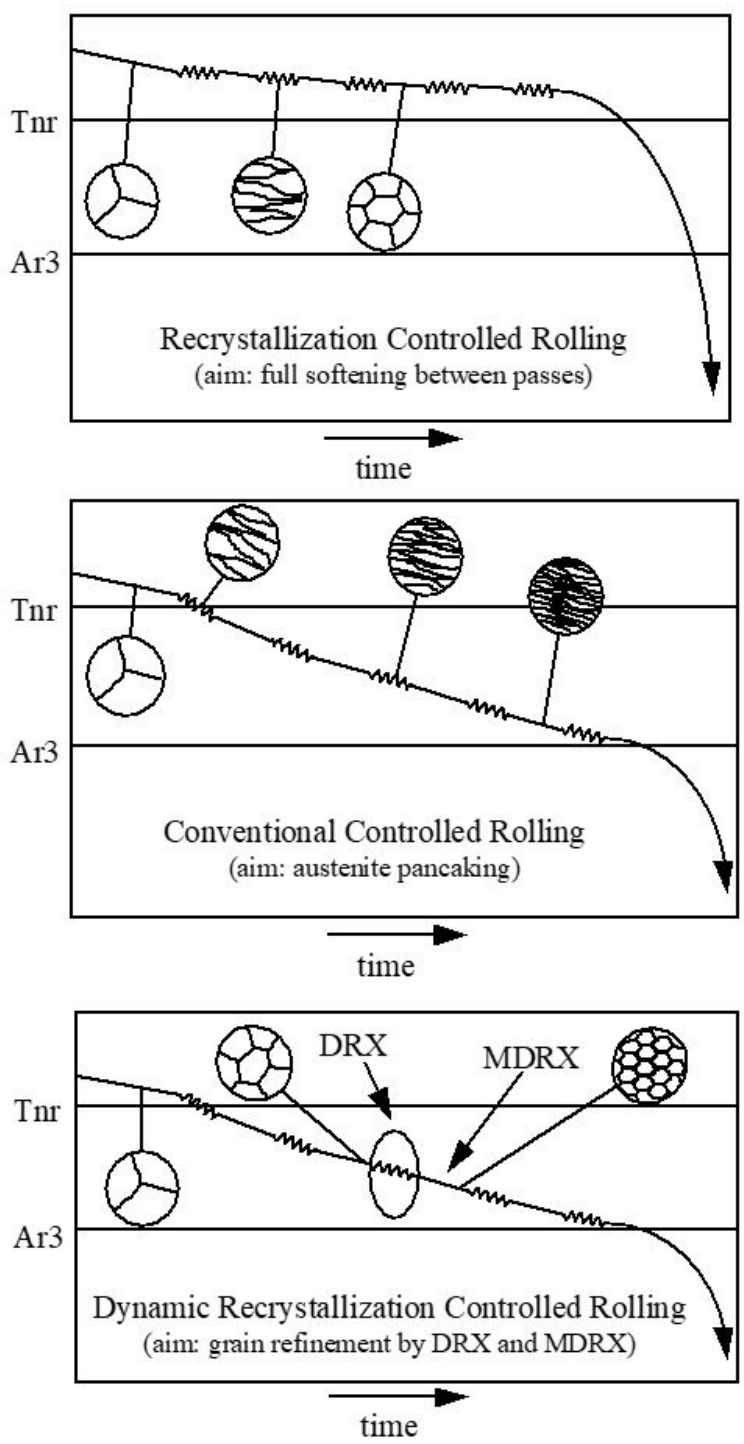

Figure I. Schematic representation of the three traditional TMCP strategies indicating the critical rolling temperatures and the evolution of the TMCP [6].

\section{THE DYNAMIC TRANSFORMATION OF FERRITE (DTF) DURING DEFORMATION}

Another important mechanism that has been studied more recently is the strain-induced dynamic transformation of ferrite above Ae3 temperatures [19-24]. The information got to date shows that it is a material response for the imposition of strain, so that ferrite is formed above Ae3 during deformation. The transformation will reduce the mean-flow-stress since at high temperatures above Ae3 ferrite is softer as compared to the austenite.

High temperature deformation experiments were performed Gleeble physical simulation system attached to the synchrotron beam line of the Brazilian Synchrotron Light Laboratory (LNLS) in Campinas-Brazil. The National Synchrotron Light Laboratory (LNLS) is 


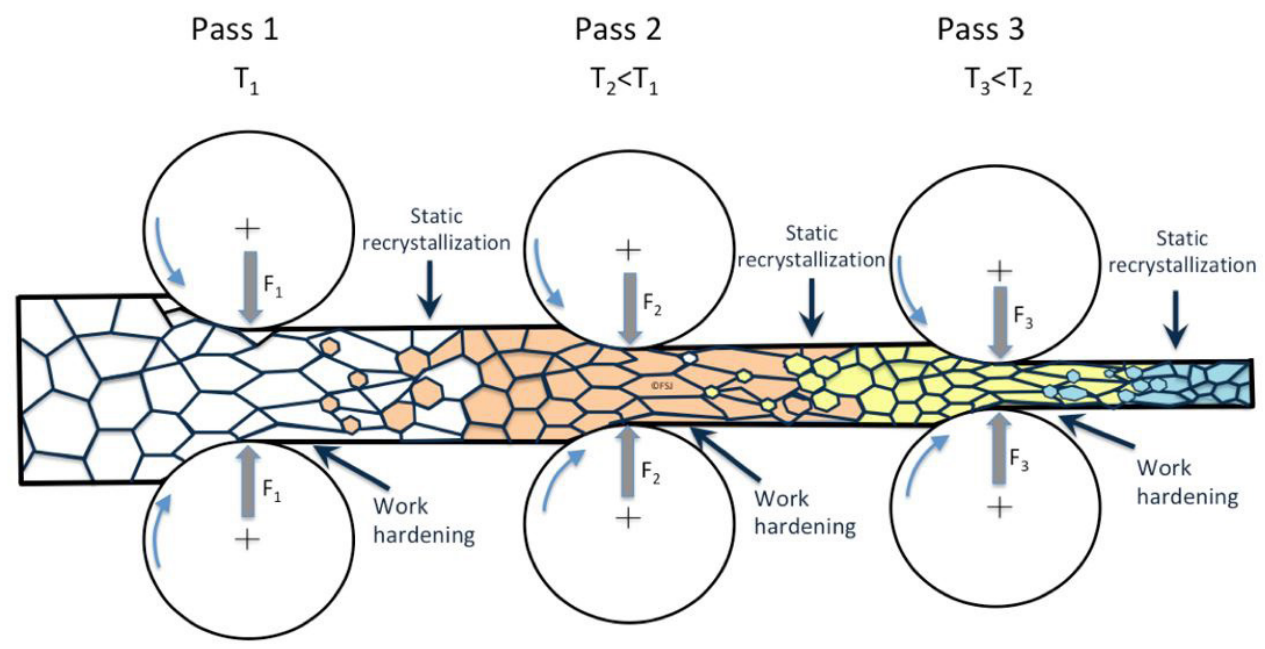

Figure 2. Schematic representation of the microstructure evolution during the recrystallization controlled rolling process [18]. $\mathrm{T}$ is the temperature, $\mathrm{F}$ is the roll force.

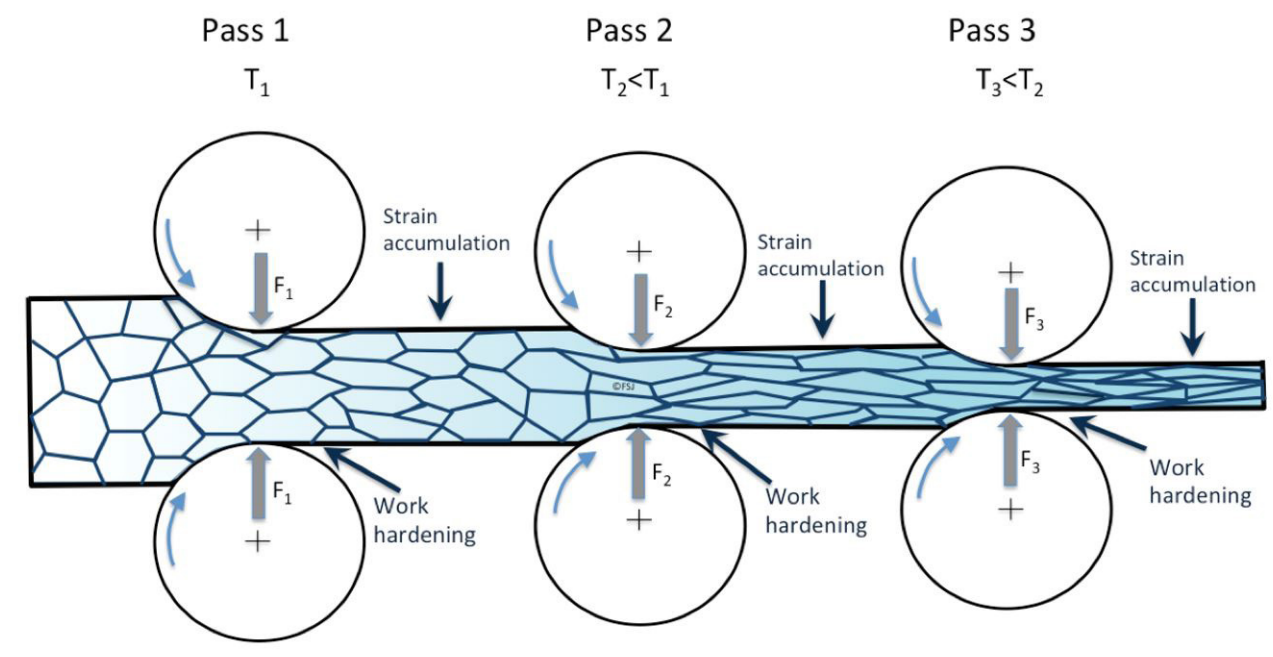

Figure 3. Schematic representation of the microstructure evolution during the conventional controlled rolling process [18]. T is the temperature, $\mathrm{F}$ is the roll force.

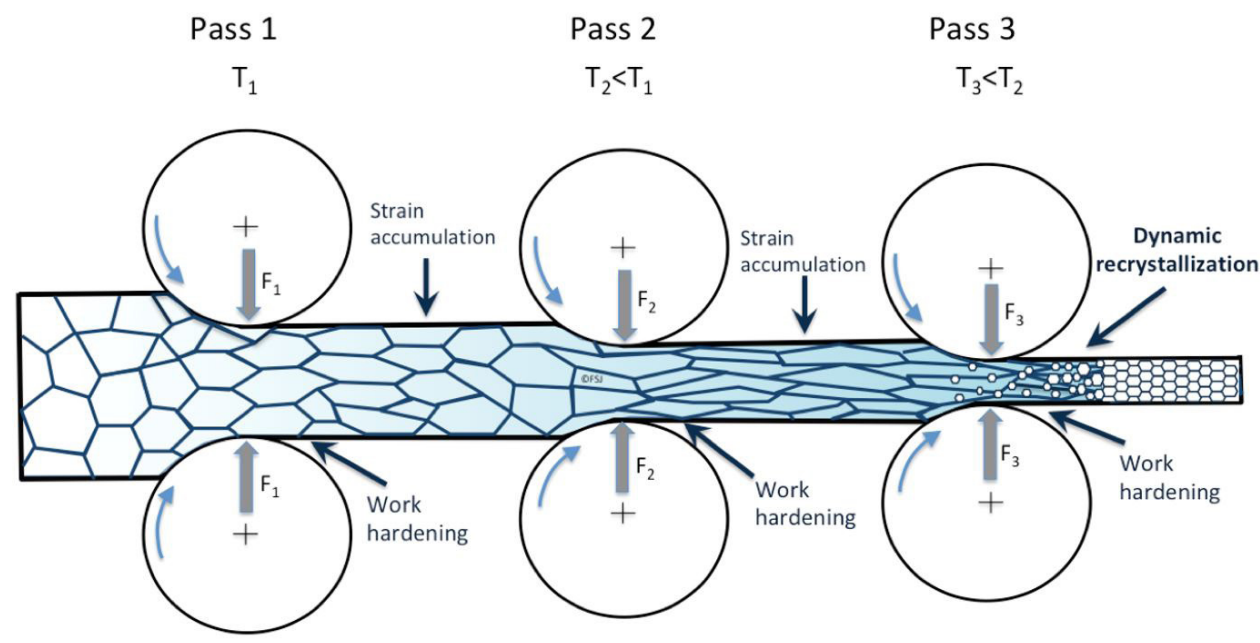

Figure 4. Schematic representation of the microstructure evolution during the dynamic recrystallization controlled rolling process [18]. $\mathrm{T}$ is the temperature, $\mathrm{F}$ is the roll force. 
a multidisciplinary institution, linked to the National Center for Research in Energy and Materials (CNPEM) and operated by the Brazilian Association of Synchrotron light technology (ABTLus) through management contract with the Ministry of science and technology (MCT). LNLS houses the only source of Synchrotron Light in Latin America and it is the only facility with a Gleeble system worldwide (Figure 5).

A microalloyed steel was used for the experiments and the chemical composition is displayed in Table $1.10 \mathrm{~mm}$ diameter cylindrical compression specimens were machined and tested according to Figure 6 below.

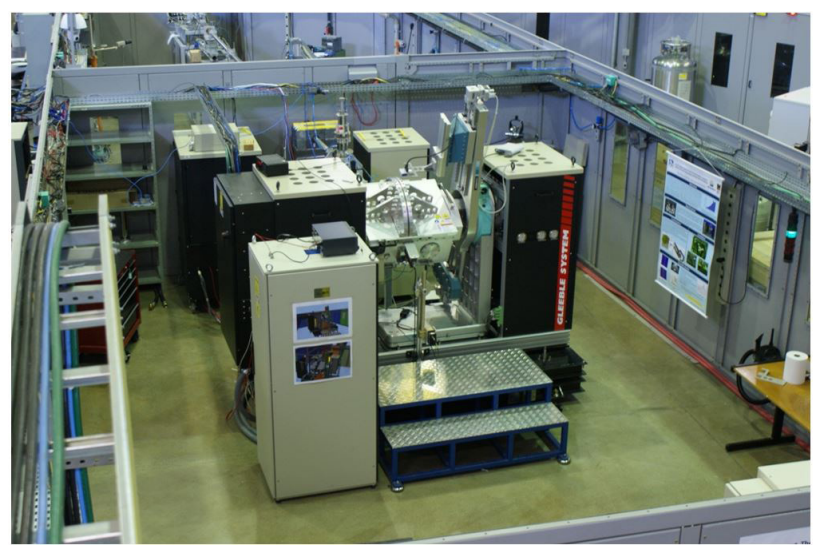

Figure 5. LNLS facilities with the specially designed Gleeble system.

Table I. Chemical composition (mass\%) and equilibrium transformation temperatures $\left({ }^{\circ} \mathrm{C}\right)$

\begin{tabular}{cccc}
\hline $\mathbf{C}$ & $\mathbf{M n}$ & $\mathbf{S i}$ & Others \\
\hline 0.05 & 1.60 & 0.25 & $\mathrm{Ti}, \mathrm{Nb}, \mathrm{V}, \mathrm{Cr}$ \\
Orthoequilibrium & $\mathrm{Ae3}$ & & Paraequilibrium Ae3 \\
$845^{\circ} \mathrm{C}$ & & $810^{\circ} \mathrm{C}$ \\
\hline
\end{tabular}

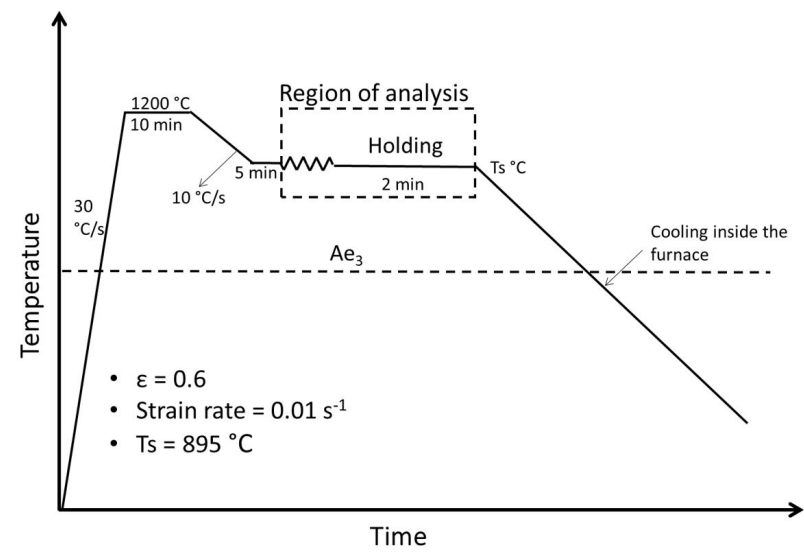

Figure 6. Test schedule of the compression samples of steel. Ts is the testing and analysis temperature.
Undoubtful evidences of DTF were obtained in the experiments carried out at the LNLS using synchrotron light $x$-ray diffraction. At temperatures $50^{\circ} \mathrm{C}$ above Ae3, ferrite diffraction peaks were found during deformation. $X$-ray diffraction was performed with Is intervals during before, during and after deformation and peaks of ferrite appeared during and immediately after the deformation.

Figures 7a to 7c show X-ray diffraction patterns during and after deformation showing clear evidence of ferrite at $895^{\circ} \mathrm{C}$, which was $50^{\circ} \mathrm{C}$ above Ae3 for the steel investigated.

It is possible to observe direct evidence that after deformation stopped, DTF was retransformed into austenite.

a)
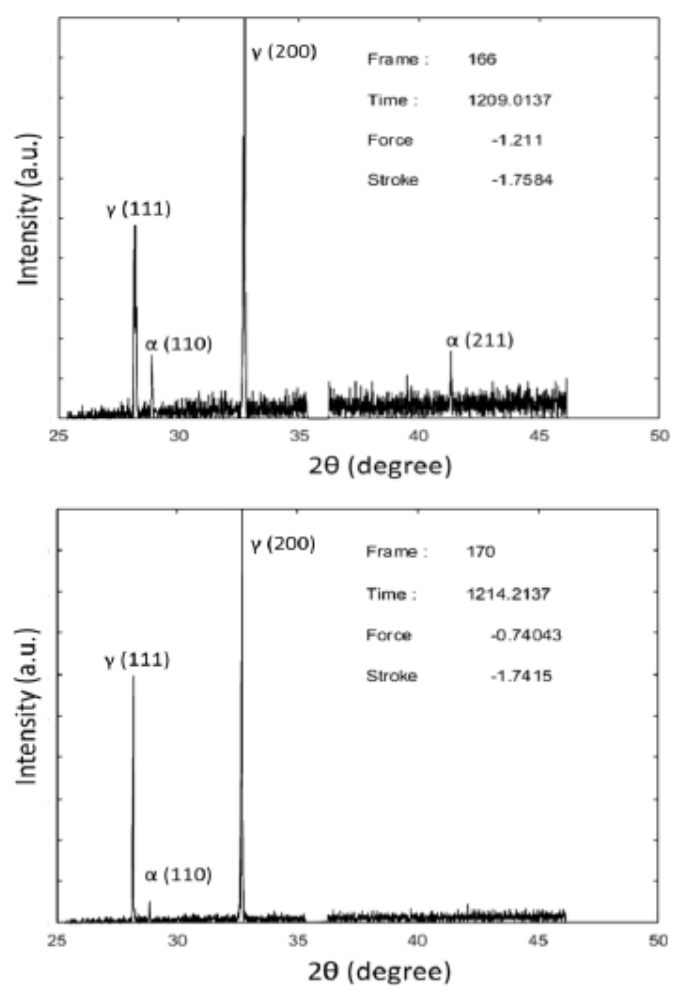

c)

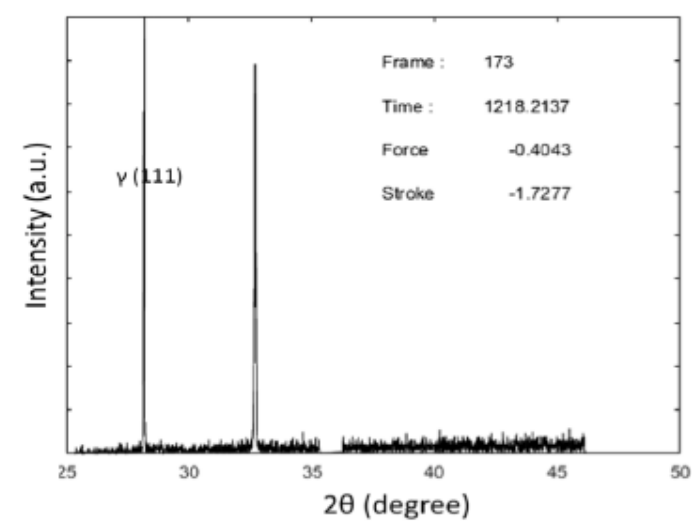

Figure 7. X-ray spectrum patterns taken (a) during final stage of deformation (b) 5 seconds after unloading and (c) 9 seconds after unloading. 


\section{DTF INTERACTION WITH STATIC AND DYNAMIC RECRYSTALLIZATION MODES}

In a preliminary analysis, two cases will be considered: static recrystallization (SRX) softening and dynamic + metadynamic recrystallization (DRX/MDRX) softening. In case of SRX softening mode, DTF should retransform into austenite while SRX grains are being nucleated and a low interaction is expected. In case of DRX/MDRX softening mode, the dynamically-transformed ferrite is formed before DRX occurs since the critical strains for DTF are smaller than the ones for DRX [25]. The dynamically transformed ferrite then retransforms into austenite and the DRX mechanism takes place normally, usually followed by MDRX in steel rolling. In this way, the sequence of sequential steps forecast in the rolling deformation zone and interpass time is as follows:

\section{I SRX Softening Mode}

In the deformation zone (above Ae3):

I. austenite work hardening;

II. formation of dynamically-transformed ferrite.

In the interpass time (above Ae3):

I. nucleation and growth of statically recrystallized grains;

II. dynamically-transformed ferrite retransforms into austenite.

\subsection{DRX/MDRX Softening Mode}

In the deformation zone (above Ae3):

I. work hardening;

II. formation of dynamically-transformed ferrite;

III. formation of dynamically recrystallized grains.

In the interpass time (above Ae3):

I. growth of dynamically recrystallized grains as metadynamic recrystallization;

II. dynamically-transformed ferrite retransforms into austenite.

The proposed mechanisms has not yet been studied in detail during hot rolling, however the results to date allow to propose the sequence above. In this particular sequence, both dynamically-transformed ferrite and dynamically-recrystallized new grains may result in high levels of grain refinement [24].

Finally, it is important to remark that all the above recrystallization mechanisms fell into the Laws of Recrystallization [5] published by Burke and Turnbull in 1952 as follows. The laws I, 2, 4, 5 and 6 applicable to recrystallization phenomena during TMCP. (i) "A minimum deformation is needed to initiate recrystallization". Every event of recrystallization follow this law;

(ii) "The temperature at which recrystallization occurs decreases as the time of anneal increases". The recrystallization kinetics is time-temperature dependent;

(iii) "The temperature at which recrystallization occurs decreases as strain increases". The higher the reduction in rolling, the lower is the temperature required for recrystallization due to the increased driving force;

(iv) "The recrystallized grain size depends primarily on the amount of deformation, being smaller for large amounts of deformation". The number of nucleation sites increases with increasing strains generating smaller final grain sizes in the rolled product;

$(v, v i)$ "For a given amount of deformation the recrystallization temperature will be increased by: (i) A larger starting grain size". Main nucleation mechanism during hot rolling is the strain-induced grain boundary migration, therefore the higher the grain boundary area, the higher is the nuclei formed and smaller resulting grain size. (ii) "A higher deformation temperature". Due to recovery, lower driving force and nucleation sites are present and therefore, the resulting grain sizes are larger.

Besides the fact that TMCP is a modern technology, the basic Laws of Recrystallization cover most of the metallurgical mechanisms applied.

\section{SUMMARY}

The dynamic transformation of ferrite mechanism was proposed to operate during hot rolling under the static and dynamic/metadynamic recrystallization regimes. Further investigations are necessary to clarify the proposed sequence of metallurgical events during hot rolling of steels. Three main rolling strategies were presented, where the dynamic recrystallization controlled rolling was the one with the most complex control in industrial facilities. It is of primary importance that all the mechanisms are considered, analyzed and well understood for a successful trial and mass production.

\section{Acknowledgements}

Authors are indebted to the LNLS (Brazilian Synchrotron Light Laboratory) for the use of the XTMS Gleeble system, with special thanks to Mr. Leonardo Wu who greatly supported the experiments carried out. 


\section{REFERENCES}

I LeBon AB. Using laboratory simulations to improve rolling schedules and equipment. In: Microalloying'75 Proceedings; 1975; Washington, D.C. New York: Union Carbide Corporation; 1975. p. 90-99.

2 Sellars CM. Modelling-an interdisciplinary activity. In: Yue S, editor. International Symposium on Mathematical Modelling of Hot Rolling of Steel: Proceedings; 1990; Hamilton, Ont. Montréal: Canadian Institute of Mining and Metallurgy; 1990. p. I-18.

$3 \mathrm{McQueen} \mathrm{HJ,} \mathrm{Jonas} \mathrm{JJ.} \mathrm{Recovery} \mathrm{and} \mathrm{recrystallization} \mathrm{during} \mathrm{high} \mathrm{temperature} \mathrm{deformation.} \mathrm{In:} \mathrm{Arsenault} \mathrm{RJ,} \mathrm{editor.}$ Treatise on materials science and technology. Vol. 6. New York: Academic Press; 1975. p. 393-493.

4 Pickering FB. High-strength-low-alloy steels- a decade of progress. In: Microalloying'75 Proceedings; 1975; Washington, D.C. New York: Union Carbide Corporation; 1975. p. 9-3I.

5 Burke JE, Turnbull D. Recrystallization and grain growth. In: Chalmers B, editor. Progress in metal physics. Vol. 3. London: Pergamon Press; 1952. p. 220-292.

6 Siciliano F. Mathematical modeling of the hot strip rolling of niobium microalloyed steels [thesis]. Montreal: McGill University; 1999.

7 Jonas JJ, Sellars CM. Future developments of metals and ceramics. London: Institute of Materials; 1992. I48 p.

8 Sarmento EC, Evans J. Effect of strain accumulation and dynamic recrystallisation on the flow stress of HSLA steels during flat rolling. In: Proceedings of an International Symposium on Processing, Microstructure, and Properties of HSLA Steels; 1992; Pennsylvania. Warrendale: ISS-AIME; 1992. p. I05-I I 2.

9 Siciliano F, Jonas JJ. Mathematical modeling of the hot strip rolling of Nb microalloyed, Cr-Mo and plain C-Mn steels. Metallurgical and Materials Transactions A, Physical Metallurgy and Materials Science. 2000;3 I (2):5 I I-530.

10 Siciliano F, Minami K, Maccagno TM, Jonas JJ. Mathematical modeling of the mean flow stress, fractional softening and grain size during the hot strip rolling of C-Mn steels. ISIJ International. 1996;36(I2): I500-I 506.

I I Minami K, Siciliano F, Maccagno TM, Jonas JJ. Mathematical modeling of mean flow stress during the hot strip rolling of Nb steels. ISIJ International. 1996;36(I2): I507-I5I5.

12 Kirihata A, Siciliano F, Maccagno TM, Jonas JJ. Mathematical modelling of mean flow stress during the hot strip rolling of multiply-alloyed medium carbon steels. ISIJ International. I997;38(2): I87-I95.

13 Kang KB, Cho SH, Siciliano F, Jonas JJ. Mathematical modeling of the hot strip rolling of Nb, Nb-V, Nb-V-Mo and $\mathrm{Nb}-\mathrm{V}$-Ti microalloyed steels. In: Proceedings of the 4th International Conference on HSLA Steels; 2000; Xi'an, China. Beijing: The Chinese Society for Metals; 2000.

I4 Siciliano F. Mathematical modelling of hot rolling: a practical tool to improve rolling schedules and steel properties. Materials Science Forum. 2013;762:210-217.

15 Pussegoda LN, Hodgson PD, Jonas JJ. Design of dynamic recrystallization controlled rolling schedules for seamless tube rolling. Materials Science and Technology. 1992;8(I):63-7I.

16 Pussegoda LN, Yue S, Jonas JJ. Laboratory simulation of seamless tube piercing and rolling using dynamic recrystallization schedules. Metallurgical Transactions. 1990;2 IA(I): I53-I64.

17 Samuel FH, Yue S, Jonas JJ, Zbinden BA. Modeling of flow stress and rolling load of a hot strip mill by torsion testing. ISIJ International. 1989;29(I0):878-886.

18 Siciliano F. Metallurgical-based mathematical model. Revista ABM: Metalurgia, Materiais e Mineração. 2015;71:438-442.

19 Yada H, Matsumura Y, Senuma T. Proceedings of the International Conference on Martensitic Transformations. Sendai, Japan: Japan Institute of Metals; 1986. p. 5 I5.

20 Yada H, Matsumura Y, Senuma T. A new thermomechanical heat treatment for grain refining in low carbon steels. In: Proceedings of the Ist International Conference on Physical Metallurgy of Thermomechanical Processing of Steels and Other Metals (THERMEC '88); 1988; Keidanren Kaikan, Tokyo, Japan. Tokyo: ISIJ; I 988. p. 200.

2I Yada H, Li CM, Yamagata H. Dynamic $\gamma-\alpha$ transformation during hot deformation in Iron-Nickel-Carbon alloys. ISIJ International. 2000;40(2):200-206.

22 Ghosh C, Aranas C Jr, Jonas JJ. Dynamic transformation of deformed austenite at temperatures above the Ae3. Progress in Materials Science. 2016;82:15I-233.

23 Rodrigues SF, Aranas C Jr, Sun B, Siciliano F, Yue S, Jonas JJ. Effect of grain size and residual strain on the dynamic transformation of austenite under plate rolling conditions. Steel Research International. 20I8;89(6): I 700547.

24 Zhao L, Park N, Tian Y, Chen S, Shibata A, Tsuji N. Novel thermomechanical processing methods for achieving ultragrain refinement of low-carbon steel without heavy plastic deformation. Materials Research Letters. 20I7;5(I):6I-68.

25 Rodrigues SF, Aranas C Jr, Siciliano F, Jonas JJ. Dynamic transformation during the simulation of plate rolling in an X70 steel. Steel Research International. 2017;88(8):1600388.

Received: I Nov. 2019

Accepted: 6 Nov. 2019

Tecnol. Metal. Mater. Miner., São Paulo, v. I7, n. 2, p. 90-95, abr./jun. 2020 